\title{
In-hospital and long-term outcomes of congestive heart failure: Predictive value of B-type and amino-terminal pro-B-type natriuretic peptides and their ratio
}

\author{
YUXIANG DAI $^{1,2^{*}}$, JUN YANG $^{3 *}$, ATSUTOSHI TAKAGI $^{1}$, HAKUOH KONISHI $^{1}$, TETSURO MIYAZAKI ${ }^{1}$, \\ HIROSHI MASUDA ${ }^{1}$, KAZUNORI SHIMADA ${ }^{1}$, KATSUMI MIYAUCHI ${ }^{1}$ and HIROYUKI DAIDA ${ }^{1}$ \\ ${ }^{1}$ Department of Cardiology, Juntendo University Hospital, Tokyo 113-8421, Japan; \\ ${ }_{2}^{2}$ Shanghai Institute of Cariovascular Diseases, Zhongshan Hospital, Fudan University, Shanghai 200032; \\ ${ }^{3}$ Department of Cardiovascular Medicine, Zaozhuang Municipal Hospital, Zaozhuang, Shandong 277100, P.R. China
}

Received December 19, 2015; Accepted January 26, 2017

DOI: 10.3892/etm.2017.4686

\begin{abstract}
Relative changes in B-type natriuretic peptide (BNP) and amino terminal pro-BNP (NT-proBNP) levels may help to assess the risk of congestive heart failure (CHF). However, whether these levels at the time of admission enable the prediction of outcomes with acute exacerbation remains unknown. The current study determined the abilities of BNP, NT-proBNP and their ratio to predict in-hospital and long-term outcomes of patients with CHF. Patients who were admitted to the cardiac care unit of Juntendo University Hospital (Tokyo, Japan) with acute CHF onset were consecutively enrolled into the present observational study. Serum levels of BNP and NT-proBNP were immediately measured on admission, and other biomarkers and clinical data were also investigated. Of 195 enrolled patients, 16 (8.2\%) succumbed to CHF in hospital and $124(69.3 \%)$ reached the endpoint of mortality or readmission following a median follow-up of 14 months. Multiple linear regression analysis revealed body mass index, low density lipoprotein cholesterol, hemoglobin, estimated glomerular filtration rate and C-reactive protein as independent predictors of the NT-proBNP/BNP ratio. BNP, NT-proBNP and their ratio were significantly higher among those who succumbed to $\mathrm{CHF}$ than in those who remained alive in hospital $(\mathrm{P}<0.05)$. Logistic regression analysis indicated that the ratio was an independent predictor for in-hospital mortality and long-term outcomes. In conclusion, the ratio of NT-proBNP to BNP more effectively predicts
\end{abstract}

Correspondence to: Professor Hakuoh Konishi, Department of Cardiology, Juntendo University Hospital, 2-1-1 Hongo, Bunkyo-ku, Tokyo 113-8421, Japan

E-mail: daiyyuxing@yeah.net

*Contributed equally

Key words: biomarker, mortality rates, heart failure, brain natriuretic peptides in-hospital outcomes than either factor alone and it may also help to predict outcomes among patients with acute exacerbation of $\mathrm{HF}$.

\section{Introduction}

Measurement of serum biomarkers including B-type natriuretic peptide (BNP) and amino terminal pro-BNP (NT-proBNP) has become important in evaluating the risk of congestive heart failure (CHF) (1-6). The 32-amino acid polypeptide $\mathrm{BNP}$ is secreted by cardiac myocytes in response to excessive distension and stretching of the cardiac wall and it has a half-life of $20 \mathrm{~min}$ (range, 18-22 $\mathrm{min}$ ) $(7,8)$. The biologically inactive 76-amino acid N-terminal fragment NT-proBNP is co-secreted with BNP and it has a half-life of $\sim 90$ min (range, 60-120 min) (9,10). The diverse physiological effects of BNP include natriuresis and peripheral vasodilation, as well as inhibition of the renin-angiotensin-aldosterone and sympathetic nervous systems $(11,12)$.

Understanding the level of BNP or NT-proBNP may provide an early diagnosis and guide for $\mathrm{CHF}$ therapy $(1,5,13,14)$. The level of BNP and NT-proBNP at the time of discharge from hospital are important in the prediction of long-term outcomes among patients with $\mathrm{CHF}(4,5)$. However, the significance of BNP and NT-proBNP levels at the time of admission remains unknown. BNP and NT-proBNP were initially regarded as interchangeable parameters in CHF. However, this concept was challenged following the discovery that BNP and NT-proBNP are cleared and degraded differently $(7,9,15,16)$. Furthermore, BNP and NT-proBNP are affected by other factors besides the severity of heart failure (HF), including obesity, renal function and inflammation (17-20). Differences between BNP and NT-proBNP in CHF assessment and the value of the NT-proBNP/BNP ratio remain unknown.

The present study aimed to determine which of these factors is the optimal marker of long-term CHF outcomes. The effects of a number of factors on the NT-proBNP/BNP ratio were analyzed and the predictive value of BNP was determined with regard to NT-proBNP and their ratios for short- and long-term outcomes of CHF. 


\section{Patients and methods}

Patients. The present study is an observational study that consecutively enrolled 195 patients with acute HF between January and December 2009. All patients provided their informed consent and approved the present study. Patients were aged 65-80 years with a mean age of 73 . All patients were hospitalized for acute $\mathrm{HF}$ and admitted to the cardiac care unit (CCU) of Juntendo University Hospital (Tokyo, Japan). Clinical and demographic information including gender, age, left ventricular ejection fraction, hypertension, New York Heart Association functional class $(13,14)$, history of ischemic heart disease, atrial fibrillation and hemodialysis were obtained from a review of medical records. Height and weight data was used to calculate the body mass index (BMI). Cardiac structure and function was determined following a standard echocardiography. The present study was performed according to the ethics policies of Juntendo University Hospital and was approved by the internal review board of the hospital.

End points. The end point for the short-term outcome was in-hospital mortality and for long-term outcomes was all-cause mortality and readmission. Follow-up ended in August 2010.

Laboratory measurements. Blood samples obtained from the patients immediately following admission to the $\mathrm{CCU}$ were sent to the clinical chemistry laboratory (Tokyo, Japan) and analyzed. Plasma BNP and NT-proBNP were analyzed using an AIA360 enzyme immunoassay analyzer (Tosho Corporation, Tokyo, Japan) and an electro-chemiluminescence immunoassay (cobas e411; Roche Diagnostics, Basel, Switzerland), respectively, according to the manufacturer's instructions. Estimated glomerular filtration rate (eGFR) was calculated according to the Modification of Diet in Renal Disease equation as follows: eGFR $\left(\mathrm{ml} / \mathrm{min} / 1.73 \mathrm{~m}^{2}\right)=186 \mathrm{x}(\mathrm{SCr})^{-1.154}$ $\mathrm{x}(\text { age })^{-0.203} \mathrm{x}(0.742$ if female), where $\mathrm{SCr}$ represents serum creatinine level $(9,15)$.

Statistical analysis. All variables were analyzed using the normal distribution test. Discrete variables are presented as frequency counts and ratios (\%). Continuous variables are expressed as mean \pm standard deviation when normally distributed, and otherwise as medians (inter-quartile range). Proportions and means/medians were compared using the $\chi^{2}$ test, Student's t-test, one-way analysis of variance and the Mann-Whitney U test. Univariate correlations were tested in the context of normality using Pearson's correlation coefficient. Correlations among non-normally distributed variables were assessed using Spearman's rank correlation ( $\rho$ ). Variables with a non-normal distribution were log-transformed prior to entry into the regression model. The results were statistically analyzed using JMP 8.0 software (SAS Institute Inc., Cary, NC, USA). All probabilities were two-tailed, and $\mathrm{P}<0.05$ was considered to represent a statistically significant difference.

\section{Results}

Patient characteristics. The study population included 195 patients aged 65-80 years, with acute onset of HF. The patients' demographics, primary disease, cardiac function
Table I. Baseline clinical characteristics of patients enrolled onto the present study $(\mathrm{n}=195)$.

\begin{tabular}{|c|c|}
\hline Characteristics & Values \\
\hline \multicolumn{2}{|l|}{ Demographics } \\
\hline Age, years ${ }^{\mathrm{a}}$ & $73(65,80)$ \\
\hline Gender, male/female ${ }^{\mathrm{b}}$ & $123(63.1) / 72(36.9)$ \\
\hline \multicolumn{2}{|l|}{ Primary disease } \\
\hline Ischemic heart disease $^{b}$ & $71(36.4)$ \\
\hline Hypertensive heart disease ${ }^{b}$ & $40(20.5)$ \\
\hline $\begin{array}{l}\text { Valvular heart disease and } \\
\text { congenital heart disease }^{\mathrm{b}}\end{array}$ & $34(17.4)$ \\
\hline Dilated cardiomyopathy ${ }^{\mathrm{b}}$ & $18(11.3)$ \\
\hline \multicolumn{2}{|l|}{ Cardiac function } \\
\hline $\mathrm{LVEF}^{\mathrm{c}}, \%$ & $43.7 \pm 18.5$ \\
\hline NYHAb, II, III, IV & $81(41.5), 58(29.7), 56(28.7)$ \\
\hline $\mathrm{BNP}, \mathrm{pg} / \mathrm{ml}^{\mathrm{a}}$ & $757.8(348.9,1,554)$ \\
\hline NT-proBNP, pg/ml ${ }^{\mathrm{a}}$ & $6,258(1,873.5,18,410.3)$ \\
\hline NT-proBNP/BNP ratio ${ }^{a}$ & $8.7(5.3,14.3)$ \\
\hline \multicolumn{2}{|l|}{ Clinical presentation } \\
\hline Hemodialysis $^{\mathrm{b}}$ & $10(5.1)$ \\
\hline $\mathrm{eGFR}, \mathrm{ml} /\left(\min \cdot 1.73 \mathrm{~m}^{2}\right)^{\mathrm{a}}$ & $48.1(25.7,65.5)$ \\
\hline $\mathrm{BMI}^{3}, \mathrm{~kg} / \mathrm{m}^{2}$ & $20.3 \pm 3.7$ \\
\hline $\mathrm{Hgb}^{3}, \mathrm{mg} / \mathrm{dl}$ & $11.7 \pm 2.6$ \\
\hline LDL-C ${ }^{\mathrm{a}}, \mathrm{mg} / \mathrm{dl}$ & $96(74,119)$ \\
\hline $\mathrm{HbA} 1 \mathrm{c}, \mathrm{mmol} / \mathrm{mol}^{\mathrm{a}}$ & $5.6(5.1,6.2)$ \\
\hline $\mathrm{CRP}, \mathrm{mg} / \mathrm{l}^{\mathrm{a}}$ & $0.8(0.2,3.5)$ \\
\hline \multicolumn{2}{|l|}{ Comorbidity } \\
\hline Hypertension $^{\mathrm{b}}$ & $61(31.3)$ \\
\hline $\mathrm{DM}^{\mathrm{b}}$ & $19(9.7)$ \\
\hline Hyperlipidemia $^{\mathrm{b}}$ & $10(5.1)$ \\
\hline $\mathrm{Af}^{\mathrm{b}}$ & $38(19.5)$ \\
\hline
\end{tabular}

${ }^{\text {aD }}$ ata are expressed as median (interquartile range) due to non-normal distribution; ${ }^{b} \mathrm{n}(\%)$ and ${ }^{c}$ mean \pm standard deviation due to normal distribution. LVEF, left ventricular ejection fraction; NYHA, New York Heart Association; BNP, B-type natriuretic peptide; NT-proBNP, amino-terminal pro-B-type natriuretic peptide; NT-proBNP/BNP, ratio of NT-proBNP to BNP; eGFR, estimated glomerular filtration rate; $\mathrm{BMI}$, body mass index; Hgb, hemoglobin; LDL-C, low density lipoprotein cholesterol; CRP, C-reactive protein; DM, diabetes mellitus; HbA1c, glycated hemoglobin; Af, atrial fibrillation.

evaluation, clinical presentation and comorbidities are presented in Table I.

Factors affecting NT-proBNP/BNP ratio. Multiple linear regression analysis demonstrated that BMI, low density lipoprotein cholesterol (LDL-C), hemoglobin (Hgb), eGFR and $\mathrm{C}$-reactive protein (CRP) were independent predictors of the NT-proBNP/BNP ratio. Further univariate correlation analysis indicated that BNP, NT-proBNP and their ratios were significantly and negatively associated with BMI, Hgb and eGFR, and positively associated with CRP. These findings indicated that BMI, Hgb, eGFR and CPR affect NT-proBNP more than 
Table II. Multiple linear regression and univariate Spearman correlation analysis to assess influence of variables on BNP, NT-proBNP and NT-proBNP/BNP.

Multiple linear regression analysis

$(\mathrm{r} 2=0.62)$
Univariate Spearman correlation analysis

\begin{tabular}{|c|c|c|c|c|c|c|c|c|}
\hline \multirow[b]{2}{*}{ Variable } & \multicolumn{2}{|c|}{ NT-proBNP/BNP } & \multicolumn{2}{|c|}{ NT-proBNP/BNP } & \multicolumn{2}{|c|}{$\mathrm{BNP}$} & \multicolumn{2}{|c|}{ NT-proBNP } \\
\hline & Estimated coefficient & P-value & $\rho$ & P-value & $\rho$ & P-value & $\rho$ & P-value \\
\hline BMI & -0.25 & 0.04 & -0.19 & 0.02 & -0.22 & $<0.01$ & -0.16 & 0.05 \\
\hline LDL-C (log) & -12.90 & $<0.01$ & -0.36 & $<0.01$ & -0.01 & 0.89 & -0.13 & 0.12 \\
\hline $\mathrm{Hgb}$ & -0.35 & 0.04 & -0.29 & $<0.01$ & -0.16 & 0.03 & -0.22 & $<0.01$ \\
\hline eGFR (log) & -18.60 & $<0.01$ & -0.58 & $<0.01$ & -0.46 & $<0.01$ & -0.52 & $<0.01$ \\
\hline CRP (log) & 3.21 & $<0.01$ & 0.33 & $<0.01$ & 0.15 & 0.05 & 0.19 & 0.02 \\
\hline Age (log) & -13.20 & 0.09 & 0.04 & 0.62 & 0.02 & 0.81 & 0.02 & 0.80 \\
\hline Gender (male) & 2.18 & 0.21 & -0.02 & 0.83 & 0.01 & 0.91 & 0.03 & 0.68 \\
\hline LVEF & 0.05 & 0.25 & 0.04 & 0.68 & -0.28 & 0.01 & -0.16 & 0.07 \\
\hline HbA1c $(\log )$ & 0.28 & 0.98 & -0.07 & 0.40 & -0.07 & 0.34 & -0.10 & 0.22 \\
\hline CK $(\log )$ & 1.04 & 0.59 & 0.11 & 0.17 & 0.05 & 0.52 & 0.05 & 0.52 \\
\hline
\end{tabular}

Log, logarithmic transformed values applied due to non-normal distribution; BNP, B-type natriuretic peptide; NT-proBNP, amino-terminal pro-B-type natriuretic peptide; NT-proBNP/BNP, ratio of NT-proBNP and BNP; $\rho$, Spearman's rank correlation; BMI, body mass index; LDL-C, low density lipoprotein cholesterol; Hgb, hemoglobin; eGFR, estimated glomerular filtration rate; CRP, C-reactive protein; LVEF, left ventricular ejection fraction; HbA1c, glycated hemoglobin; CK, creatine kinase.
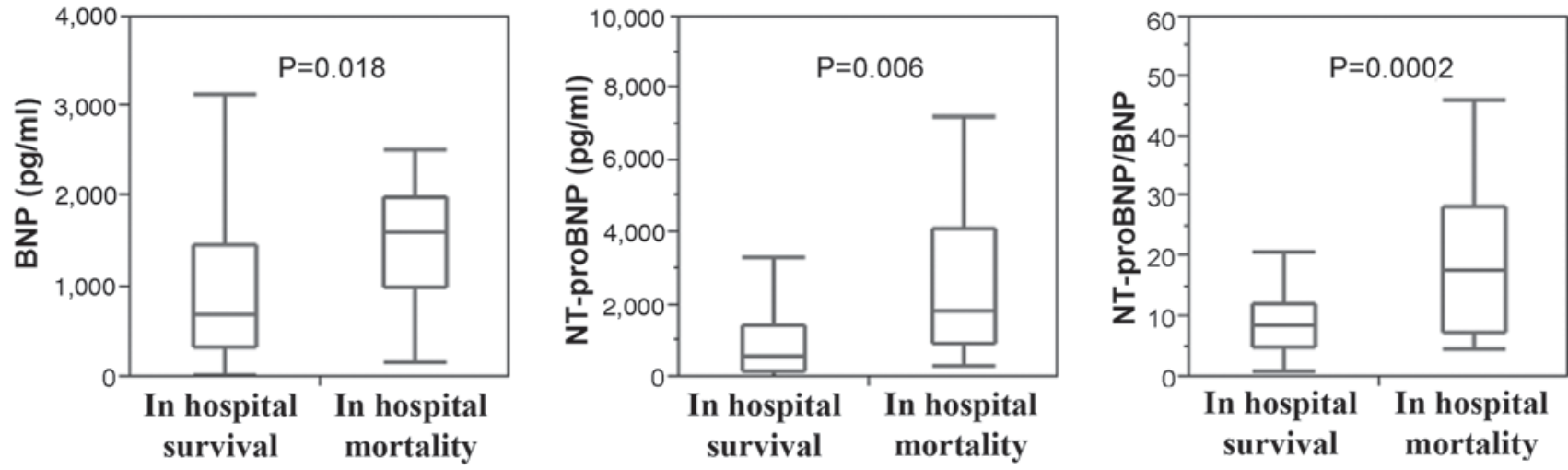

Figure 1. BNP, NT-proBNP and ratio of NT-proBNP to BNP levels of patients in hospital. A total of 16 patients succumbed to heart failure and 179 survived in hospital. Values of BNP [700.0 (331.2-1,465.9) vs. 1,613.7 (997.6-1,981.4), $\mathrm{P}=0.018]$, NT-proBNP $[5,358(1,525-14,169)$ vs. 18,449 $(9,068-41,093), \mathrm{P}=0.006]$ and NT-proBNP/BNP ratio [8.4 (5.0-12.3) vs. 17.6 (7.3-28.3), $\mathrm{P}=0.0002]$ are significantly higher in the group who succumbed to heart failure in hospital than those who survived. BNP, B-type natriuretic peptide; NT-proBNP, amino-terminal pro-BNP.

BNP. A significant and negative association was identified between LDL-C and NT-proBNP/BNP, but not with either NT-proBNP or BNP (Table II).

Predictive value of in-hospital mortality and long-term outcome. A total of $16(8.2 \%)$ patients succumbed to HF in hospital and $124(69.3 \%)$ had an endpoint of mortality or readmission following a median follow-up of 14 months (range, 8-20 months).

A11 BNP [700.0 (331.2-1,465.9) vs. 1613.7 (997.6-1,981.4), P<0.05], NT-proBNP [5,358 (1,525-14,169] vs. $18,449(9,068-41,093), \mathrm{P}<0.01]$ and the ratio of NT-proBNP to BNP [8.4 (5.0-12.3) vs. 17.6 (7.3-28.3), $\mathrm{P}<0.01]$ were significantly increased in the patients who succumbed to HF, compared with those who remained alive while in hospital (Fig. 1). Logistic regression analysis including NT-proBNP/BNP, NT-proBNP and BNP indicated that the NT-proBNP/BNP ratio was the only independent predictor of in-hospital mortality (Table III). The Kaplan-Meier survival curves for all-cause mortality and readmission are presented in Fig. 2 for BNP, NT-proBNP and the NT-proBNP/BNP ratio, respectively. Quartiles of NT-proBNP and the NT-proBNP/BNP ratio significantly differed (log-rank test, $\mathrm{P}=0.018$ and $\mathrm{P}=0.0035$, respectively), whereas those of $\mathrm{BNP}(\log$-rank test, $\mathrm{P}=0.21) \mathrm{did}$ not. Cox proportional-hazard models of long-term outcomes including NT-proBNP/BNP, NT-proBNP and BNP indicated that the NT-proBNP/BNP ratio remained the only independent predictor of long-term outcomes (Table IV). 
Table III. Logistic regression analysis of in-hospital mortality of 16 patients.

\begin{tabular}{lccc}
\hline & \multicolumn{2}{c}{$\begin{array}{c}\text { Model includes NT-proBNP/BNP, } \\
\text { adjusted }\end{array}$} & $\begin{array}{c}\text { Model includes NT-proBNP and BNP, } \\
\text { adjusted }\end{array}$ \\
\cline { 2 - 4 } Variable & Estimated coefficient & P-value & Estimated coefficient \\
\hline NT-proBNP/BNP $(\log )$ & -10.200 & 0.038 & - \\
BNP $(\log )$ & - & - & 11.900 \\
NT-proBNP $(\log )$ & - & - & -14.800 \\
Age $(\log )$ & -15.400 & 0.100 & 12.500 \\
Gender $(\operatorname{male})$ & 1.740 & 0.150 & 1.620 \\
BMI & 0.349 & 0.200 & 0.250 \\
fEF & 0.080 & 0.130 & 0.071 \\
Hgb & -0.812 & 0.130 & -0.742 \\
eGFR $(\log )$ & -2.490 & 0.370 & -2.730 \\
LDL-C $(\log )$ & 1.770 & 0.670 & 6.100 \\
HbA1c $(\log )$ & -17.100 & 0.180 & 0.640 \\
CK $(\log )$ & -3.620 & 0.090 & 0.510 \\
CRP $(\log )$ & -1.860 & 0.120 & 0.420 \\
\hline
\end{tabular}

Log, logarithmic transformed values applied due to non-normal distribution; NT-proBNP, amino-terminal pro-B-type natriuretic peptide; BNP, B-type natriuretic peptide; NT-proBNP/BNP, ratio of NT-proBNP and BNP; BMI, body mass index; Hgb, hemoglobin; eGFR, estimated glomerular filtration rate; LDL-C, low density lipoprotein cholesterol; CRP, C-reactive protein; LVEF, left ventricular ejection fraction; HbA1c, glycated hemoglobin; CK, creatine kinase.
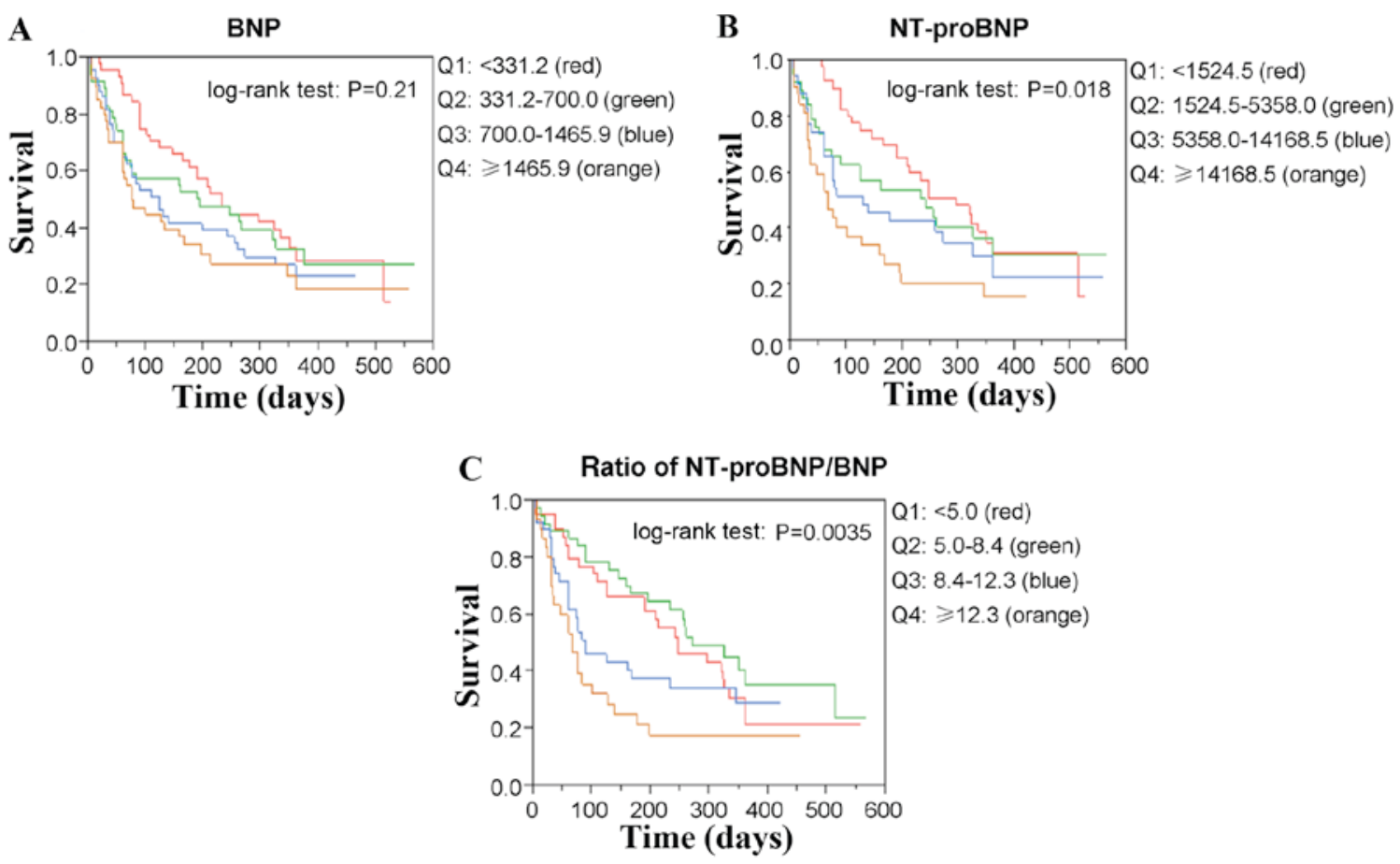

Figure 2. Kaplan-Meier survival curves for all-cause mortality and readmission stratified according to Q of (A) BNP, (B) NT-proBNP and (C) ratio of NT-proBNP to BNP. Red, green, blue and orange lines represent Q1, Q2, Q3 and Q4, respectively. Quartiles of NT-proBNP and NT-proBNP/BNP ratio (log-rank test, $\mathrm{P}=0.018$ and $\mathrm{P}=0.0035$, respectively) significantly differed, whereas those of BNP did not (log-rank test, $\mathrm{P}=0.21)$. Q, quartiles; $\mathrm{BNP}, \mathrm{B}$-type natriuretic peptide; NT-proBNP, amino-terminal pro-B-type natriuretic peptide.

\section{Discussion}

The present study demonstrated that the NT-proBNP/BNP ratio predicts the in-hospital and long-term outcomes of decompensated CHF more accurately than does the level of eitherBNP or NT-proBNP at the time of admission. The majority of previous studies $(9,15,16)$ that have aimed to assess the predictive value of BNP and NT-proBNP were based 
Table IV. Cox proportional-hazard models of long-term outcomes.

Model includes NT-proBNP/BNP, adjusted
Model includes NT-proBNP and BNP, adjusted

\begin{tabular}{|c|c|c|c|c|}
\hline \multirow[b]{2}{*}{ Variable } & & \\
\hline & HR $(95 \%$ CI $)$ & $\mathrm{P}$-value & HR $(95 \% \mathrm{CI})$ & P-value \\
\hline NT-proBNP/BNPa & $1.40(1.01-1.93)$ & 0.040 & - & - \\
\hline $\mathrm{BNP}^{\mathrm{a}}$ & - & - & $0.90(0.55-1.46)$ & 0.670 \\
\hline NT-proBNPa & - & - & $1.39(0.84-2.30)$ & 0.200 \\
\hline Gender (female) & $0.48(0.26-0.84)$ & 0.010 & $0.42(0.22-0.78)$ & 0.005 \\
\hline $\mathrm{eGFR}^{\mathrm{a}}$ & $0.63(0.44-0.89)$ & 0.009 & $0.63(0.43-0.90)$ & 0.012 \\
\hline Hemodialysis & $2.35(1.52-4.38)$ & 0.009 & $2.42(1.54-4.32)$ & 0.015 \\
\hline $\operatorname{Age}^{\mathrm{a}}$ & $1.11(0.86-1.45)$ & 0.420 & $1.12(0.85-1.47)$ & 0.420 \\
\hline NYHA & $0.82(0.54-1.24)$ & 0.350 & $0.91(0.61-1.37)$ & 0.660 \\
\hline $\mathrm{BMI}^{\mathrm{a}}$ & $1.13(0.88-1.46)$ & 0.320 & $1.19(0.90-1.57)$ & 0.220 \\
\hline $\mathrm{LDL}^{\mathrm{a}}{ }^{\mathrm{a}}$ & $0.91(0.72-1.15)$ & 0.410 & $0.88(0.69-1.12)$ & 0.290 \\
\hline $\mathrm{Hgb}^{\mathrm{a}}$ & $0.93(0.68-1.26)$ & 0.640 & $0.88(0.63-1.22)$ & 0.440 \\
\hline $\mathrm{HbA} 1 c^{a}$ & $0.93(0.72-1.20)$ & 0.580 & $0.89(0.69-1.16)$ & 0.400 \\
\hline $\mathrm{CRP}^{\mathrm{a}}$ & $0.95(0.73-1.23)$ & 0.700 & $0.98(0.75-1.27)$ & 0.860 \\
\hline
\end{tabular}

${ }^{\mathrm{a}} \mathrm{All}$ continuous variables transformed to ordinal data according to quartiles. HR was calculated between quartiles of these variables. HR, hazard ratio; CI, confidence interval; NT-proBNP, amino-terminal pro-B-type natriuretic peptide; BNP, B-type natriuretic peptide; NT-proBNP/BNP, ratio of NT-proBNP and BNP; eGFR, estimated glomerular filtration rate; NYHA, New York Heart Association; BMI, body mass index; LDL-C, low density lipoprotein cholesterol; Hgb, hemoglobin; CRP, C-reactive protein; HbA1c, glycated hemoglobin.

on data at the time of discharge, when these levels may be more stable than at the time of admission and reflect the basic and long-term ventricular status. However, an increase at the time of discharge provides more current information about exacerbation in acute HF. Therefore, the current study predicted in-hospital and long-term outcomes of CHF on the basis of the level of BNP and NT-proBNP upon admission.

Cardiac myocytes synthesize proBNP that is then transformed into hormonally active BNP and inactive NT-proBNP. Although it is suggested that they are released from the heart in equimolar amounts, their half-lives and clearance pathways differ (7-9). Plasma clearance of BNP is achieved via binding to natriuretic peptide receptor type C (NPR-C) and proteolysis by neutral endopeptidases, whereas NT-proBNP is primarily cleared by renal excretion $(15,16)$. Exogenous atrial natriuretic peptide (ANP) has been applied as part of a treatment strategy for CHF (15). Both ANP and BNP competitively bind to natriuretic peptide receptors but NT-proBNP does not. Nishiyama et al (20) reported that infused exogenous ANP (carperitide) influenced plasma BNP but not NT-proBNP. Therefore, plasma BNP and NT-proBNP are of similar relevance to the diagnosis and prognosis of HF but they are not equal and each has a different role in the assessment of $\mathrm{HF}$ due to different biological activities and sensitivities to pharmacological therapy.

According to the method of Jensen et al (21), the current study assumed that BNP and NT-proBNP are produced at the same constant rate with a similar distribution volume in a one-compartment model, and that the production and elimination rates are equal. The calculated NT-proBNP/BNP ratio is 10.9, when the supposed half-lives of BNP and NT-proBNP are 20 and $90 \mathrm{~min}$, respectively. However, the median value of the
eNT-proBNP/BNP ratio in the present study was 8.7 (5.3-14.3), which was potentially due to differences in the influence of renal dysfunction on the elimination rate of NT-proBNP and BNP.

The mammalian natriuretic peptide system consists of the neurohormones, ANP, BNP, C-type natriuretic peptide (CNP) and NT-proBNP. ANP, BNP and CNP have a common 17-amino acid ring structure in which the majority of the amino acid residues are conserved. Atrial myocytes release stored 28-amino acid ANP in response to atrial distension and stretching $(15,16)$. The physiological actions of ANP are similar to those of BNP, including a reduction in systemic vascular resistance and central venous pressure and an increase in natriuresis (22). The ANP level has been demonstrated to be significant in the prognosis of patients with atrial fibrillation and CHF (23-25). However, BNP and NT-BNP appear superior to ANP in the diagnosis of HF due to a closer association with echocardiographic evidence of left ventricular dysfunction and a longer half-life. Thus, the present study primarily focused on BNP and NT-proBNP to reflect ventricular status.

The present study demonstrated that the major factors affecting the NT-proBNP/BNP ratio included dystrophic status (BMI, LDL-C), anemia (Hgb), renal dysfunction (eGFR) and inflammation (CRP). Renal function (17,18,26,27), obesity (28-30) and inflammation $(19,21)$ are non-cardiac factors that should be considered during BNP and NT-proBNP evaluations.

The levels of BNP and NT-proBNP increase in patients with renal failure (16). The clearance of NT-proBNP may be more reliant upon renal filtration and the levels may thus increase in response to renal failure to a greater extent than those of BNP, since BNP is also cleared by receptor-mediated 
uptake and protease action; therefore, the NT-proBNP/BNP ratio would increase (31-33). Jensen et al (21) suggested that the increased NT-proBNP/BNP ratio is due to inflammation increasing the level of NT-proBNP more than that of BNP. Inflammation may increase BNP clearance mediated by protease or receptors, thus balancing the increase in BNP production. As NT-proBNP is not affected by these clearance mechanisms, NT-proBNP is elevated to a larger extent by inflammation, leading to an increased NT-proBNP/BNP ratio. The mechanism of different effects of dystrophic status and anemia on NT-proBNP and BNP remains unknown. However, changes in the level of NPR-C, receptor-mediated uptake and protease action in dystrophic and anemia status may be one explanation.

Previous studies have primarily focused on the predictive value of NT-proBNP and BNP and both have been demonstrated to be predictors of $\mathrm{CHF}(9,16)$. However, each has advantages and disadvantages in predicting the outcomes of CHF: BNP has a shorter half life and may theoretically reflect more recent ventricular status, whereas NT-proBNP has greater stability and provides more information, but not regarding ventricular tension and function. Thus, the NT-proBNP/BNP ratio provides considerable information about parameters including renal dysfunction, nutrition status, anemia and inflammation, and may therefore serve as a new index in combination with other biomarkers. The NT-proBNP/BNP ratio may be a more useful and accurate predictor of CHF than single biomarkers.

Although the present study indicated some interesting results, there were also a few limitations. Firstly, the present study involved relatively small sample amounts. We would involve a larger patient sample in a further study. Secondly, the predictive function of the NT-proBNP to the BNP combining method has not been compared with the classical methods fully in a clinical setting. We will compare the present method with the classical methods in a further study.

In conclusion, the NT-proBNP/BNP ratio is an improved predictor of in-hospital and long-term outcomes of $\mathrm{CHF}$, compared with BNP or NT-proBNP alone. The NT-proBNP/BNP ratio is negatively associated with $\mathrm{Hgb}, \mathrm{eGFR}, \mathrm{BMI}$ and positively with CRP, as each variable exerts different effects on NT-proBNP and BNP. Anemia, renal dysfunction, inflammation and dystrophic status affect NT-proBNP more than they affect BNP. Thus, the NT-proBNP/BNP ratio may be useful to predict the short- and long-term outcomes of patients with acute exacerbation of HF.

\section{References}

1. Bozkurt B and Mann DL: Use of biomarkers in the management of heart failure: Are we there yet? Circulation 107: 1231-1233, 2003.

2. Jortani SA, Prabhu SD and Valdes R Jr: Strategies for developing biomarkers of heart failure. Clin Chem 50: 265-278, 2004.

3. Harrison A and Amundson S: Evaluation and management of the acutely dyspneic patient: The role of biomarkers. Am J Emerg Med 23: 371-378, 2005.

4. Costello-Boerrigter LC and Burnett JC Jr: The prognostic value of N-terminal proB-type natriuretic peptide. Nat Clin Pract Cardiovasc Med 2: 194-201, 2005

5. Jarolim P: Serum biomarkers for heart failure. Cardiovasc Pathol 15: 144-149, 2006.

6. Aviles JM and Aviles RJ: Advances in cardiac biomarkers. Emerg Med Clin North Am 23: 959-975, 2005.

7. Moe GW: BNP in the diagnosis and risk stratification of heart failure. Heart Fail Monit 4: 116-122, 2005.
8. Bettencourt P: NT-proBNP and BNP: Biomarkers for heart failure management. Eur J Heart Fail 6: 359-363, 2004.

9. Richards $\mathrm{M}$ and Troughton RW: NT-proBNP in heart failure: Therapy decisions and monitoring. Eur J Heart Fail 6: 351-354, 2004.

10. Fuat A, Murphy JJ, Hungin AP, Curry J, Mehrzad AA, Hetherington A, Johnston JI, Smellie WS, Duffy V and Cawley P: The diagnostic accuracy and utility of a B-type natriuretic peptide test in a community population of patients with suspected heart failure. Br J Gen Pract 56: 327-333, 2006.

11. Moe GW: B-type natriuretic peptide in heart failure. Curr Opin Cardiol 21: 208-214, 2006.

12. Palazzuoli A, Gallotta M, Quatrini I and Nuti R: Natriuretic peptides (BNP and NT-proBNP): Measurement and relevance in heart failure. Vasc Health Risk Manag 6: 411-418, 2010.

13. McKie PM, Rodeheffer RJ, Cataliotti A, Martin FL, Urban LH, Mahoney DW, Jacobsen SJ, Redfield MM and Burnett JC Jr: Amino-terminal pro-B-type natriuretic peptide and B-type natriuretic peptide: Biomarkers for mortality in a large community-based cohort free of heart failure. Hypertension 47: 874-880, 2006.

14. Maisel AS, Krishnaswamy P, Nowak RM, McCord J, Hollander JE, Duc P, Omland T, Storrow AB, Abraham WT, Wu AH, et al: Rapid measurement of B-type natriuretic peptide in the emergency diagnosis of heart failure. N Engl J Med 347: 161-167, 2002.

15. Hayek S and Nemer M: Cardiac natriuretic peptides: From basic discovery to clinical practice. Cardiovasc Ther 29: 362-376, 2011.

16. Valle R and Aspromonte N: Use of brain natriuretic peptide and bioimpedance to guide therapy in heart failure patients. Contrib Nephrol 164: 209-216, 2010.

17. van Kimmenade RR, Januzzi JL Jr, Bakker JA, Houben AJ, Rennenberg R, Kroon AA, Crijns HJ, van Dieijen-Visser MP, de Leeuw PW and Pinto YM: Renal clearance of B-type natriuretic peptide and amino terminal pro-B-type natriuretic peptide a mechanistic study in hypertensive subjects. J Am Coll Cardiol 53: 884-890, 2009.

18. Tagore R, Ling LH, Yang H, Daw HY, Chan YH and Sethi SK: Natriuretic peptides in chronic kidney disease. Clin J Am Soc Nephrol 3: 1644-1651, 2008.

19. Bednarek-Skublewska A, Zaluska W and Ksiazek A: The relationship between serum level of N-terminal pro-B-type natriuretic peptide and nutritional status, and inflammation in chronic hemodialysis patients. Clin Nephrol 73: 14-20, 2010.

20. Nishiyama K, Tsutamoto T, Tanaka T, Fujii M, Yamamoto T, Yamaji M and Horie M: Plasma NT-proBNP as a more reliable biomarker of endogenous cardiac natriuretic peptides than BNP during carperitide infusion. Int Heart J 50: 183-190, 2009.

21. Jensen J, Ma LP, Fu ML, Svaninger D, Lundberg PA and Hammarsten O: Inflammation increases NT-proBNP and the NT-proBNP/BNP ratio. Clin Res Cardiol 99: 445-452, 2010.

22. De Bold AJ: Atrial natriuretic factor: A hormone produced by the heart. Science 230: 767-770, 1985.

23. Clerico A, Iervasi G, Del Chicca MG, Emdin M, Maffei S, Nannipieri M, Sabatino L, Forini F, Manfredi C and Donato L: Circulating levels of cardiac natriuretic peptides (ANP and BNP) measured by highly sensitive and specific immunoradiometric assays in normal subjects and in patients with different degrees of heart failure. J Endocrinol Invest 21: 170-179, 1998.

24. Rienstra M, Van Gelder IC, Van den Berg MP, Boomsma F and Van Veldhuisen DJ: Natriuretic peptides in patients with atrial fibrillation and advanced chronic heart failure: Determinants and prognostic value of (NT-)ANP and (NT-pro)BNP. Europace 8: 482-487, 2006.

25. Falcão LM, Pinto F, Ravara L and van Zwieten PA: BNP and ANP as diagnostic and predictive markers in heart failure with left ventricular systolic dysfunction. J Renin Angiotensin Aldosterone Syst 5: 121-129, 2004.

26. Vanderheyden M, Bartunek J, Filippatos G, Goethals M, Vlem BV and Maisel A: Cardiovascular disease in patients with chronic renal impairment: Role of natriuretic peptides. Congest Heart Fail 14 (4 Suppl 1): 38-42, 2008.

27. Bayes-Genis A, DeFilippi C and Januzzi JL Jr: Understanding amino-terminal pro-B-type natriuretic peptide in obesity. Am J Cardiol 101: 89-94, 2008.

28. Sugisawa T, Kishimoto I, Kokubo Y, Makino H, Miyamoto Y and Yoshimasa Y: Association of plasma B-type natriuretic peptide levels with obesity in a general urban Japanese population: The Suita Study. Endocr J 57: 727-733, 2010.

29. Srisawasdi P, Vanavanan S, Charoenpanichkit $\mathrm{C}$ and Kroll MH: The effect of renal dysfunction on BNP, NT-proBNP, and their ratio. Am J Clin Pathol 133: 14-23, 2010. 
30. Kälsch H, Neumann T and Erbel R: Less increase of BNP and NT-proBNP levels in obese patient with decompensated heart failure: Interpretation of natriuretic peptides in obesity. Int J Cardiol 133: e22-e24, 2009.

31. deFilippi CR, Seliger SL, Maynard S and Christenson RH: Impact of renal disease on natriuretic peptide testing for diagnosing decompensated heart failure and predicting mortality. Clin Chem 53: 1511-1519, 2007.
32. DeFilippi C, van Kimmenade RR and Pinto YM: Amino-terminal pro-B-type natriuretic peptide testing in renal disease. Am J Cardiol 101: 82-88, 2008

33. McCullough PA and Sandberg KR: B-type natriuretic peptide and renal disease. Heart Fail Rev 8: 355-358, 2003. 